
e-ISSN 2016/Atual: 2525-7870 | e-ISSN 2015/2016: 2447-018X

\title{
A mulher na literatura: seus enquadramentos e a precariedade da emancipação
}

\author{
Mujeres en la literatura: sus realizaciones y la precariedad de
}

emancipación

\author{
The woman in the literature: its frameworks and the precariousness of \\ emancipation
}

Bruna Cordeiros Lira ${ }^{1}$

\begin{abstract}
Resumo
A figura histórica feminino presente na literatura do século XVI, por exemplo, expõe um cenário literário sem representatividade feminina em suas obras. A composição da narrativa sobre a mulher estava a cargo de escritores homens, que insuficientemente versavam acerca das mulheres, mas que revelavam a exclusão e repressão feminina nos meios acadêmicos e sociais. Desta forma Virginia Woolf em "Um teto todo seu" traça panoramas históricos e sociais sobre a restrição do sexo feminino a literatura, tanto no acesso a leituras e a aprendizagem, fontes intelectuais que as embase e a liberdade cerceada socialmente de produzir no meio literário e acadêmico. Envolta em uma sociedade excludente, há fomento a uma construção social que desprivilegia a mulher como agente das escritas literárias, inviabilizando a sua emancipação intelectual ao longo da história. Calcado nestes elementos, a teoria do capital humano de Michel Foucault estabelece dialogo sobre as condições de subjugação patriarcal das mulheres, juntamente com o investimento em capital humano não ofertado a elas da mesma forma que aos homens na sociedade. Juntamente com a autora Judith Butler em "Vida precária, vida passível de luto", há o questionamento teórico sobre o livro de Woolf acerca do enquadramento produzido por uma literatura sexista e excludente, que de forma rasa ou insuficiente via a mulher como um agente social, inferiorizando a sua existência.
\end{abstract}

Palavras-chave: mulheres; literatura; Virginia Woolf; Judith Butler; Michel Foucault.

\section{Resumen}

La figura histórica de la mujer en la literatura del siglo XVI, por ejemplo, expone una escena literaria sin representación femenina en sus obras. La composición de la narración de la mujer estaba a cargo de los hombres escritores que insuficientemente versavam acerca de las mujeres, pero reveló la exclusión de las mujeres y la represión en los antecedentes académicos y sociales. De este modo Virginia Woolf en "Todo un techo de su" traza panoramas históricos y sociales de la literatura femenina limitación, tanto en el acceso a la lectura y el aprendizaje, fuentes intelectuales que embase y recorte de las libertades socialmente para producir el medio literario y académica. Envuelto en una sociedad excluyente, no está fomentando una construcción social que desprivilegia mujeres como agentes de escritos literarios, invalidando su emancipación intelectual largo de la historia. Calzado estos elementos, la teoría del capital humano de Michel Foucault establece un diálogo sobre las condiciones de sometimiento patriarcal de las mujeres, junto con la inversión en capital humano no se les ofrece la misma manera que los hombres en la sociedad. Junto con Judith Butler, autor de "vida precaria, la vida capaz de luto", está la cuestión teórica sobre el libro de Woolf por el medio ambiente producida por una literatura sexista y excluyente de esa manera superficial o mujeres vieron insuficientes como un agente social, inferiorizando su existência.

Palabras claves: mujeres; literatura; Virginia Woolf; Judith Butler; Michel Foucault.

\footnotetext{
${ }^{1}$ Graduanda em História; Universidade Federal do Pampa - Unipampa; Jaguarão, Rio Grande do Sul, Brasil; bruna.cordeiroslira@gmail.com.
} 

e-ISSN 2016/Atual: 2525-7870 | e-ISSN 2015/2016: 2447-018X

\begin{abstract}
The female historical figure in the literature of the sixteenth century, for example, exposes a literary scene without female representation in their works. The composition of the narrative of the woman was in charge of men writers who insufficiently versavam about women, but revealed the female exclusion and repression in academic and social backgrounds. Thus Virginia Woolf in "A whole roof its" traces historical and social panoramas of the female constraint literature, both in access to reading and learning, intellectual sources that embase and curtailed freedom socially to produce the literary medium and academic. Wrapped in an exclusionary society, there is fostering a social construction that desprivilegia women as agents of literary writings, invalidating their intellectual emancipation throughout history. Footware these elements, the human capital theory of Michel Foucault establishes dialogue on the conditions of patriarchal subjugation of women, together with investment in human capital not offered them the same way as men in society. Along with Judith Butler author in "precarious life, life capable of mourning," there is the theoretical question about Woolf's book about the environment produced by a sexist and exclusionary literature that shallow way or insufficient saw women as a social agent, inferiorizando its exisistence.
\end{abstract}

Keywords: Woman, literature, Virginia Woolf, Judith Butler, Michel Foucault

\title{
1. Introdução
}

Em "Um teto todo seu”, Virginia Wolf expõe situações do cotidiano social do século XVII, XVIII que pairavam sobre a vida das mulheres e fundamentam o machismo visto na sociedade até os dias atuais, apesar do livro datar de mais de meio século atrás. Com esses elementos a tese de que a mulher necessita de um teto que seja somente seu é embasada em independência financeira galgando a independência do núcleo familiar que a reprime, liberdade de se expressão e construir aquilo que é de sua vontade, sem depender das amarras do patriarcado na tomada de decisões de sua vida.

A obra de Woolf estabelece dialogo com Judith Butler acerca de sua teoria sobre a precariedade das vidas humanas e o enquadramento que se dá, voltando este elemento para a vida precária das mulheres e a visão delas na literatura, cunhada com a sua atuação na mesma. No tocante a obra de Foucault o embasamento teórico se desenvolve através da teoria do capital humano de investimento feito em um ser humano para que isto atribua valor perante o capitalismo. No caso das mulheres, o investimento no capital humano é provado por Woolf na coerção intelectual e emancipatória da mulher na sociedade historicamente.

\section{A construção do livro "Um teto todo seu" sobre a atuação da mulher na literatura}

A explanação de Virginia Woolf denota a importância de indagar onde estão as mulheres perante os livros literários, de que forma são representadas deles e principalmente que elementos as impede de escrever justamente sobre elas mesmas. Woolf apresenta o nome do livro como ponto central do desenvolvimento da narrativa e dos objetivos "A mulher precisa ter dinheiro e um teto todo dela se pretende mesmo escrever ficção" (WOOLF, 1929, 
p. 8). A partir de tal afirmação uma narrativa que é colocada como sendo ficcional ou não, é desenvolvida pela autora, denotando compor parte de sua vivência para a sua tese.

A narrativa versa sobre a estranheza, ainda na época do entre guerras mundiais, de como a mulher era vista no meio acadêmico. A academia aparentava hostilidade a atuação de uma mulher, limitando até mesmo o acesso livre a biblioteca e necessitando de uma visita guiada e supervisionada, afinal o acesso feminino a determinados livros era fundamentalmente restrito.

Foi assim que me vi caminhando com extrema rapidez por um gramado. Imediatamente, um vulto de homem ergueu-se para interceptar-me. Nem percebi, a princípio, que os gestos daquela pessoa de aparência curiosa, de fraque e camisa engomada, eram a mim dirigidos. Seu rosto revelava horror e indignação. O instinto, mais que a razão, veio em meu auxílio: ele era um Bedel; eu era uma mulher. (WOOLF, 1929, p. 10)

Levanta-se explanações de que forma as mulheres eram colocadas e vistas na sociedade? Porque não eram relatadas nos livros? E fundamentando os panoramas de seus questionamentos encontram-se a extrema dificuldade de uma mulher em ser agente literária, consumir literatura e ter oportunidades para isso. Justamente por condições de estrutura social como a dependência financeira de seus maridos, pois não era dado as mulheres o pleno direito de exercer trabalhos fora do âmbito familiar e mesmo que assim fosse, os frutos financeiros de seu esforço passariam alienavelmente para o domínio financeiro de seu marido. $\mathrm{Na}$ sociedade a mulher era vista como propriedade do homem que a desposava, por tanto tudo que era dela a ele pertencia, além da prerrogativa das mulheres não lidarem com o financeiro de suas famílias.

O papel social da mulher era extremamente limitado e excludente socialmente. Alguns autores do século XVII, XVIII afirmavam que jamais uma mulher escreveria como Shakespeare, por exemplo, mas de uma forma pejorativa, que no ensaio é fundamentado como uma afirmação real, mas não por incapacidade da mulher, mas por restrição social e falta de oportunidade. Possivelmente existiriam mulheres com o mesmo ímpeto de se tornar letrada, com fundos intelectuais, mas que a sociedade da época coibia qualquer insinuação por parte destas mulheres que ousavam subverter o protagonismo dos homens. Não havia espaço para tais formas de pensar e ver a sociedade do ângulo feminino, e se assim havia o desejo por parte de uma mulher, provavelmente ela seria submetida a percalços duros e de resistência intensa da sociedade.

[...] é que qualquer mulher nascida comum grande talento no século XVI teria certamente enlouquecido, se matado com um tiro, ou terminado seus dias em algum 
chalé isolado, fora da cidade, meio bruxa, meio feiticeira, temida e ridicularizada. Pois não é preciso muito conhecimento de psicologia para se ter certeza de que uma jovem altamente dotada que tentasse usar sua veia poética teria sido tão contrariada e impedida pelas outras pessoas, tão torturada e dilacerada pelos próprios instintos conflitantes, que teria decerto perdido a saúde física e mental. (WOOLF, 1929, p. 62)

\section{O enquadramento feminino na literatura e a precariedade da emancipação}

A produção literária atuou perante as mulheres de forma idealizadora ao tratar do feminino. Duarte (1987, p. 1) dá ênfase principalmente sobre a produção literária, resultante direto dos movimentos feministas na década de 60 e 70, e pretendeu/pretende principalmente, destruir os mitos da inferioridade natural, resgatar a história das mulheres, reinvidicar a condição do sujeito na investigação da própria história, além de rever, criticamente, o que homens até então, tinham escrito a respeito.

Voltando para uma análise dos acontecimentos históricos, na mitologia poderia se identificar muitas deusas que remetiam a sensualidade e fertilidade, por exemplo, em ideários do movimento naturalista que tinha a figura da mulher ligada a natureza e nas produções positivistas relacionado a mulher a um símbolo da ideologia. Porém no caso essas narrativas forjam um fundo que não condiz com a subjugação da mulher na sociedade no decorrer da história.

\footnotetext{
Na imaginação, ela é da mais alta importância; em termos práticos, é completamente insignificante. Atravessa a poesia de uma ponta à outra; por pouco está ausente da história. Domina a vida de reis e conquistadores na ficção; na vida real, era escrava de qualquer rapazola cujos pais lhe enfiassem uma aliança no dedo. Algumas das mais inspiradas palavras, alguns dos mais profundos pensamentos saem-lhe dos lábios na literatura; na vida real, mal sabia ler e escrever e era propriedade do marido. (WOOLF, 1929, p. 56).
}

Abordando a subjugação feminina com relação aos escritos de Judith Butler acerca da precariedade das vidas humanas e os enquadramentos dados aos casos, podemos estabelecer fundamentos para o livro de Woolf. Butler trata a forma com que a vulnerabilidade de uma vida pode ser subjugada quando é identificada, ela expõe que ao reconhecer a precariedade em um indivíduo há duas atitudes a serem tomadas sob, ajudar aquele que necessita deste empenho ou subjuga-lo, explorar e tirar vantagens da precariedade de uma outra vida.

A precariedade da vida das mulheres é notória ao longo da história através de tutela da sua liberdade, cerceamento de decisões, vulnerabilidade de respeito dentro da sociedade, tendo a necessidade de reafirmar constantemente o quão humana ela é e deve ser respeitada em sua integralidade. $\mathrm{O}$ reconhecimento de um ser como vida passível de luto, termo que 
Judith faz uso, também perpassa a consciência de quanto vale a vida de uma pessoa para nos permitirmos sentir a sua perda como algo de fato doloroso e relevante.

\begin{abstract}
Afirmar que uma vida pode ser lesada, por exemplo, ou que pode ser perdida, destruída ou sistematicamente negligenciada até a morte é sublinhas não somente a finitude de uma vida (o fato de que a morte é certa), mas também sua precariedade (porque acida requer que várias condições sociais e econômicas sejam atendidas para ser mantida como uma vida). A precariedade implica viver socialmente, isto é, o fato de que a vida de alguém está sempre, de alguma forma, nas mãos de outro. (BUTLER, 1929, p. 31)
\end{abstract}

No caso das mulheres o luto é algo a ser questionado diante dos contextos históricos. A vida de uma mulher é constantemente ameaçada exclusivamente pelo fato de ser uma mulher, elas são tidas como propriedades e moeda de troca para acordos matrimoniais a séculos. É de tal vulnerabilidade que sua precariedade causa o desejo de subjuga-la, como menciona Butler. E essa condição da mulher na sociedade é apresentada constantemente na narrativa de Virginia Wolf para fundamentar as bases de "Um teto todo seu", justamente para diminuir a resistência, subjugação do patriarca na sociedade que o sexo feminino deve construir as bases de seu alicerce para só assim tem a liberdade mínima de exercer os seus desejos.

O enquadramento usado por Butler como sendo os enfoques que os meios de comunicação ou sociais dão para terminado grupo social, noticia, ideologia e fundamentos sociais compartilha paralelos com Wolf, no sentido de analisar o enquadramento que ela expõe da mulher na literatura. O feminino é negligenciado e quando mencionado é visto de uma forma idealizada que não ultrapassa as barreiras do machismo e nem da própria verdade sobre a mulher em sociedade. Há uma narrativa de fatos limitados, que não busca a representatividade das mulheres no meio literário e sim a visão que os homens produzem sobre o que é ou deveria ser mulher.

A história das mulheres encontrada na literatura revela a verdadeira história dos excluídos da história oficial, não ocupando o posto de agente histórico e necessitando de outros mecanismos que deem conta das suas realidades num tempo espaço. Um dos problemas, segundo (Tily, 2007; Scott, 1988) é o de saber em que medida a história das mulheres afetou a historiografia, obtendo o reconhecimento de suas descobertas como autênticos "fatos de história", para retomar a expressão de Carr (1983).

Ainda sobre a literatura critica feminista contida nas produções bibliográficas, os livros só evidenciam que o academicismo não era voltado para elas, não escrevia sobre a 
realidade do cotidiano e o silencio presente neles provocam perguntas como as de Virginia Wolf em seu ensaio.

A relação da mulher e sua liberdade financeira, de poder subsistir sem que haja a necessidade de dependência e tutela por um homem, cunhado também com a possibilidade de poder investir em si mesma, em construir sua própria história expõe um conceito usado por Foucault (1986), com relação ao capital humano. As pessoas valem no mercado capitalista aquilo que é investido em sua capacitação, isso se torna uma moeda de troca e agrega elementos aquele indivíduo. Como cita Virginia Wolf ao falar da irmã de Shakespeare:

[...] sua extraordinariamente bem-dotada irmã, suponhamos, permanecia em casa. Era tão audaciosa, tão imaginativa, tão ansiosa por ver o mundo quanto ele. Mas não foi mandada à escola. Não teve oportunidade de aprender gramática e lógica, quanto menos ler Horácio e Virgílio. Pegava um livro de vez em quando, talvez algum do irmão, e lia algumas páginas. Mas nessas ocasiões, os pais entravam e lhe diziam que fosse remendar as meias ou cuidar do guisado e que não andasse no mundo da lua com livros e papéis. (WOLF, 1929, p. 59).

A teoria do capital humano de Foucault contém dois tópicos, o capital humano na concepção genética acerca de escolhas de genes e o capital humano voltado para o investimento dedicado aos filhos. No tocante ao capital genético, Foucault aborda a escolha da genética, porém quando voltamos esta teoria para as mulheres poderíamos trabalhar a própria genética feminina perante o capitalismo e a sociedade. A mulher possui condições em seu corpo que são vistas pela sociedade patriarcal como limitadores, como a gravidez e os ciclos menstruais, por exemplo.

No entanto a construção de Foucault sobre o capital humano de investimento é de fundamental pertinência para o trabalho empoderador de Woolf em seu livro, embasando as discussões sobre investimentos intelectuais das famílias e da sociedade sob mulheres. O capital humano se desenvolve quando se tem o intuito de investir na educação, construção pessoal e social de um indivíduo e consequentemente isto será revertido em ganhos financeiros dentro do capitalismo. Porém historicamente as mulheres são privadas do mesmo direito a instrução intelectual que os homens, isto inviabiliza a sua emancipação e a igualdade de oportunidades que os homens possuem na sociedade.

Claro, é muito mais do lado do adquirido, ou seja, na constituição mais ou menos voluntaria de um capital humano no curso da vida dos indivíduos, que se colocam todos os problemas e que novos tipos de analises são apresentados pelos neoliberais. Formar capital humano, formar, portanto, essas espécies de competência-máquina que vão produzir renda, ou melhor, que vão ser remuneradas por renda, quer dizer o quê? Quer dizer, é claro, fazer o que se chama de investimentos educacionais (FOULCAULT, 1978-1979, p. 315). 


\section{Conclusões}

Através do ensaio produzido por Virginia Wolf podemos compreender e apreender de forma fundamentada e embasada sobre o contexto histórico e social que fizeram com que as mulheres sofressem tal abandono de protagonismo dentro das obras literárias. Expondo as visões dos homens que escreviam sobre as mulheres e não propondo representatividade e oportunidades para a expansão das ações das próprias mulheres sobre a sua história.

O livro propõe grande contribuição para o movimento feminista, com uma narrativa conduzida de forma branda e sucinta, facilitando o entendimento dos percalços que o sexo feminino perpassou ao longo de séculos e até os dias atuais.

A intersecção com a obra de Judith Butler é relevante importância para a explanação acerca da vulnerabilidade social que perpassa a mulher na sociedade, por conta do patriarcado que compõe as relações sociais há séculos e restringe a abrangência da atuação das mulheres. É de extrema importância a colocação do intuito de "Um teto todo seu" na busca de fomentar a existência da mulher através de seus próprios meios, se assim desejar ingressar na academia ou em qualquer instituição que a sociedade não à permita estar.

A mantença por si só deve ser ressaltada em seus valores referentes a tese de Foucault e a relevância no atentado ao capital humano das mulheres, que são privadas de escolaridade, intelectualidade e do meio acadêmico no decorrer dos anos.

\section{Referências}

WOLF, Virginia. “Um teto todo seu”. (1929).

BUTLER, Judith. "Vida precária, vida passível de luto". Quadros de guerra: quando a vida é passível de luto? (2004).

Vida precária. Contemporânea - Revista de Sociologia da UFSCar. São Carlos, Departamento e Programa de Pós-Graduação em Sociologia da UFSCar, 2011, n.1, p. 13-33.

CARR, Edward H.: What is History?. New York, Knopf. 1983, p. 10.

DUARTE, Constância Lima. Feminismo e literatura no Brasil. Estudos avançados, v. 17, n. 49, p. 151-172, 2003.

FOUCAULT, Michel. “Aula de 14 de março de 1979"; “Aula de 21 de março de 1979”. In: O nascimento da biopolítica: curso dado no College de France (1978-1979). Disponível em: https://gambiarre.files.wordpress.com/2011/01/foucault-nascimento-da-biopolc3adtica1.pdf. Acesso em 10/set/2016.

SCOTT, Joan W.: "Women's History", IN Past and Present, 101. Pp. 141-157. Republicado em Gender and the Politics of History. New York, Columbia University Press. 1988, p. 30. 
RELACult - Revista Latino-Americana de Estudos em Cultura e Sociedade

Revista Latinoamericana de Estudios en Cultura y Sociedad | Latin American Journal of Studies in Culture and Society V. 02, Ed. Especial, dezembro, 2016, p. 381-388| periodicos.claec.org e-ISSN 2016/Atual: 2525-7870 | e-ISSN 2015/2016: 2447-018X

TILLY, Louise A. Gênero, história das mulheres e história social. Cadernos Pagu, n. 3, p. 2862, 2007. 